\title{
Understanding the errors in input prescription maps based on high spatial resolution remote sensing images
}

\author{
David Gómez-Candón • Francisca López-Granados • \\ Juan J. Caballero-Novella · José M. Peña-Barragán • \\ Luis García-Torres
}

Published online: 17 June 2012

(C) The Author(s) 2012. This article is published with open access at Springerlink.com

\begin{abstract}
The aim of this study was to determine the positional accuracy of GeoEye-1 images and how it affects the delineation of the input prescription map (IPM) for sitespecific strategies. Seven panchromatic and multi-spectral GeoEye-1 satellite images were taken over the LaVentilla village area (Andalusia, Spain), from April to October 2010, at an interval of approximately 3-4 weeks. Sixteen hard-edge ground control points (GCPs) were geo-referenced using a sub-decimetre DGPS. Each DGPS-GCP position was compared with the corresponding co-ordinates for each image to determine the position error (PE) and error direction angle $\left(\Phi_{\mathrm{ge}}{ }^{\circ}\right)$. The PE and $\Phi_{\mathrm{ge}}{ }^{\circ}$ for each GCP varied slightly for any given GeoEye-1 image and the overall PE among images estimated through the root mean square error (RMSE) varied considerably. RMSE ranged from approximately 2-9 $\mathrm{m}$ and from 3.5 to $9 \mathrm{~m}$ for the panchromatic and multi-spectral images studied, respectively, and the average was approximately $6.0 \mathrm{~m}$ for each of the series of images. Consequently, the geo-referencing of GeoEye-1 images is recommended to increase the positioning accuracy. Conventional geo-referencing using GCPs provided an average RMSE of $2 \mathrm{~m}$ for the panchromatic and $3.5 \mathrm{~m}$ for the multi-spectral images. The AUGEO System ${ }^{\circledR}$ geo-referencing of the 4-May GeoEye-1 image provided an RMSE of $0.75 \mathrm{~m}$ for the panchromatic and $2.70 \pm 1.30 \mathrm{~m}$ for the multi-spectral images. The IPM delineated from remote-sensed images takes up the image geo-referencing error and, consequently, each micro-plot does not coincide with its corresponding ground-truth micro-plot. In this report, the percentage of non-overlapping area (\%NOA) has been developed as a function of the PE/RMSE, $\alpha^{\circ}$ (the angle between $\Phi_{\text {ge }}$ and the operating direction, $\Phi_{\mathrm{op}}$ ), and the micro-plot size. The $\%$ NOA consistently increased as the RMSE and $\alpha^{\circ}$ increased, and it decreased as the micro-plot width or length increased. The decision about micro-plot size should be based on the RMSE, $\alpha^{\circ}$, and the maximum admissible \%NOA. In the case of the GeoEye- 1 images studied with an average RMSE of $6 \mathrm{~m}$, a micro-plot size of $6 \times 30 \mathrm{~m}$ would have yielded an IPM inaccuracy (\%NOA) of approximately $5 \%$, assuming an $\alpha^{\circ}=0^{\circ}$.
\end{abstract}

\footnotetext{
D. Gómez-Candón · F. López-Granados · J. J. Caballero-Novella · J. M. Peña-Barragán · L. García-Torres $(\bowtie)$

Institute for Sustainable Agriculture, CSIC, P.O. Box 4084, 14080 Cordoba, Spain

e-mail: luisgarciatorres@uco.es; lgarciatorres@ias.csic.es
} 
Keywords Remote sensing · Position error/RMSE · Geo-referencing · Co-registration · Prescription map · GeoEye-1 - AUGEO $^{\circledR}$ software

\section{Introduction}

Input prescription maps (IPMs) are a key tool for the implementation of site-specific management (SSM) strategies. IPMs are generally composed of tiny rectangular plots, with an indication of the variable input rate to be applied to each tiny plot. Each tiny rectangular plot fit the area covered by a nozzle or set of nozzles of the input application machinery, and could be named as "micro-plot" (Gómez-Candón et al. 2011a). The size of the microplot varies widely, for example from approximately $1 \times 2$ to $10 \times 30 \mathrm{~m}$, with the microplot width $(W)$ equal to, or a multiple of, the width covered by a nozzle of the application machinery, and the micro-plot length $(L)$ normally a multiple of $W$. Mapping the biotic/ abiotic patch area to be treated and delineating the subsequent IPMs are critical for sitespecific strategies (SSM) implementation using remote-sensed images and, for practical reasons, both need to be matched (Ruiz et al. 2006). By assessing Avena sterilis weed infestations through remote sensing and simulating micro-plots of diverse size, GómezCandón et al. (2011b) estimated that the smaller the micro-plot area, the higher the environmental and economic benefits.

Airborne remote sensing has been successful for detection of weed patches when patches are dense and uniform and have unique spectral characteristics, requiring sub-meter resolution to identify weeds in small patches (Rew et al. 1997; Brown and Noble 2005). IPMs can be obtained from remotely sensed images through the following processes: (a) estimating the image position accuracy and geo-referencing it based on ground control points, which will be described in this paper; (b) image processing for mapping the targeted agro-environmental information, such as achieved for weed infestations by Lamb and Brown (2001) and López-Granados et al. (2006); (c) sectioning and assessing the image into micro-images through specific add-on software, such as SARI ${ }^{\circledR}$ (GómezCandón 2011a). Precision agriculture requires high-spatial-resolution images, generally of less than 3-5 m. Thus, the smaller the pixel size, the more precise the strategy. In the last decade, images from satellites, such as QuickBird, GeoEye-1 and Pleiades (SIC 2011), with spatial resolutions of 2.4, 2.0 and $1.6 \mathrm{~m}$, respectively, at the multi-spectral level and of $0.6,0.5$ and $0.5 \mathrm{~m}$, respectively, at the panchromatic level, have become commercially available and may be used for precision agriculture.

Prior to the development and proliferation of high-spatial-resolution technologies, it was fairly easy to correctly locate a field site within the correct pixel of existing images, such as LANDSAT with $28.5 \times 28.5 \mathrm{~m} \mathrm{pixel}^{-1}$, using even uncorrected GPS locations (Weber et al. 2008). However, with high-spatial-resolution images and sub-metre DGPS positioning technologies another segment of the error budget has become apparent: the georeferencing between images and field sites, such as those used for training and validation samples (Weber et al. 2008). Furthermore, some geo-referenced commercial satellite images, such as those of QuickBird, have errors of approximately 15-20 m (Toutin and Chénier 2004) and are therefore unacceptable for some precision agriculture uses. Weber et al. (2008) highlight the importance of considering the geo-referencing between imagery and field sites in the error budget, especially with studies involving high spatial resolution images and patchy target detection. Lamb et al. (1999) demonstrated that using a relatively large number of widely spaced ground control points (17) with a differential global 
position system (DGPS) accurate to $\pm 0.25 \mathrm{~m}$ in the process of warping imagery to map co-ordinates, still produced a spatial error of one pixel in the centre of an image.

A semi-automatic geo-referencing system of remote imagery for high spatial resolution named AUGEO ${ }^{\circledR}$ has been developed based on artificial terrestrial targets (ATTs) and software for the automatic location and geo-referencing of the ATTS (Gómez-Candón et al. 2011). This consists of placing a geo-referenced ATT on the ground, capturing it in the images and finding it using the AUGEO software based on its spectral-band specificity, which differentiates it from the surrounding land uses. The ATT geographic co-ordinates interact with the map registration menu of $\mathrm{ENVI}^{\circledR}$, and the image is geo-referenced based on a linear/first order function. Generally, the AUGEO system due to its software characteristics requires considerably less time than conventional geo-referencing fieldwork and the subsequent computer work, and it allows the geo-referencing of images of areas that do not contain recognisable GCPs for verification and validation.

To our knowledge, no information is available on the position accuracy estimation of the GeoEye-1 image series or how it affects the delineation of IPMs. The aim of this work was to study the suitability of GeoEye-1 images for the delineation of IPMs for precision agricultural uses. The specific objectives were as follows: (1) to determine the position accuracy of GeoEye-1 satellite images series; (2) to study comparatively the geo-referencing process accuracy of GeoEye-1 images that were achieved both conventionally and through the AUGEO system; and (3) to estimate the IPM inaccuracy, as affected by the position error and the micro-plot size.

\section{Materials and methods}

Locations and remote-sensed images

Seven multi-spectral and panchromatic GeoEye-1 satellite images (GeoEye 2011) were taken over the LaVentilla village area (province of Cordoba, Southern Spain), from April to October 2010, each of approximately $100 \mathrm{~km}^{2}$ (Fig. 1a). The geographic co-ordinates (Universe Transverse Mercator System, Zone 30 North) in the upper-left corner of the images were $X=315206 \mathrm{~m} / Y=4186133 \mathrm{~m}$. The images were taken on April 9, May 4, May 23, June 20, July 9, August 22 and October 2. The panchromatic image was $0.50 \mathrm{~m} \mathrm{pixel}^{-1}$; the multi-spectral-image spatial resolution was $2.00 \mathrm{~m} \mathrm{pixel}^{-1}$, providing information on blue $(450-510 \mathrm{~nm})$, green $(510-580 \mathrm{~nm})$, red $(655-690 \mathrm{~nm})$ and nearinfrared $(780-920 \mathrm{~nm})$ spectral bands. The swath width was $15.2 \mathrm{~km}$. The studies described below were conducted on the central area of each image, approximately 1000 ha (Fig. 1b), where the ground was predominantly flat, with average slopes of a $2.12 \%$ grade.

\section{Geo-referencing errors of GeoEye-1 images}

The Environment for Visualising Images $\left(\mathrm{ENVI}^{\circledR}\right.$ 4.6, Exelis-Visual Information Solutions, 4990 Pearl East Circle, Boulder, CO 80301, USA) software was used for visualising and processing the images. To determine the position accuracy of the GeoEye- 1 images acquired, sixteen ground control points (GCPs), such as building corners and road crossings, were identified in the central scene area (Fig. 1c) and geo-referenced using a subdecimetre DGPS Trimble model GeoExplorer 3000 series GEO-XH/2008 receiver (Trimble Co., Sunny Vale, CA 94085, USA). DGPS raw data were corrected based on the 

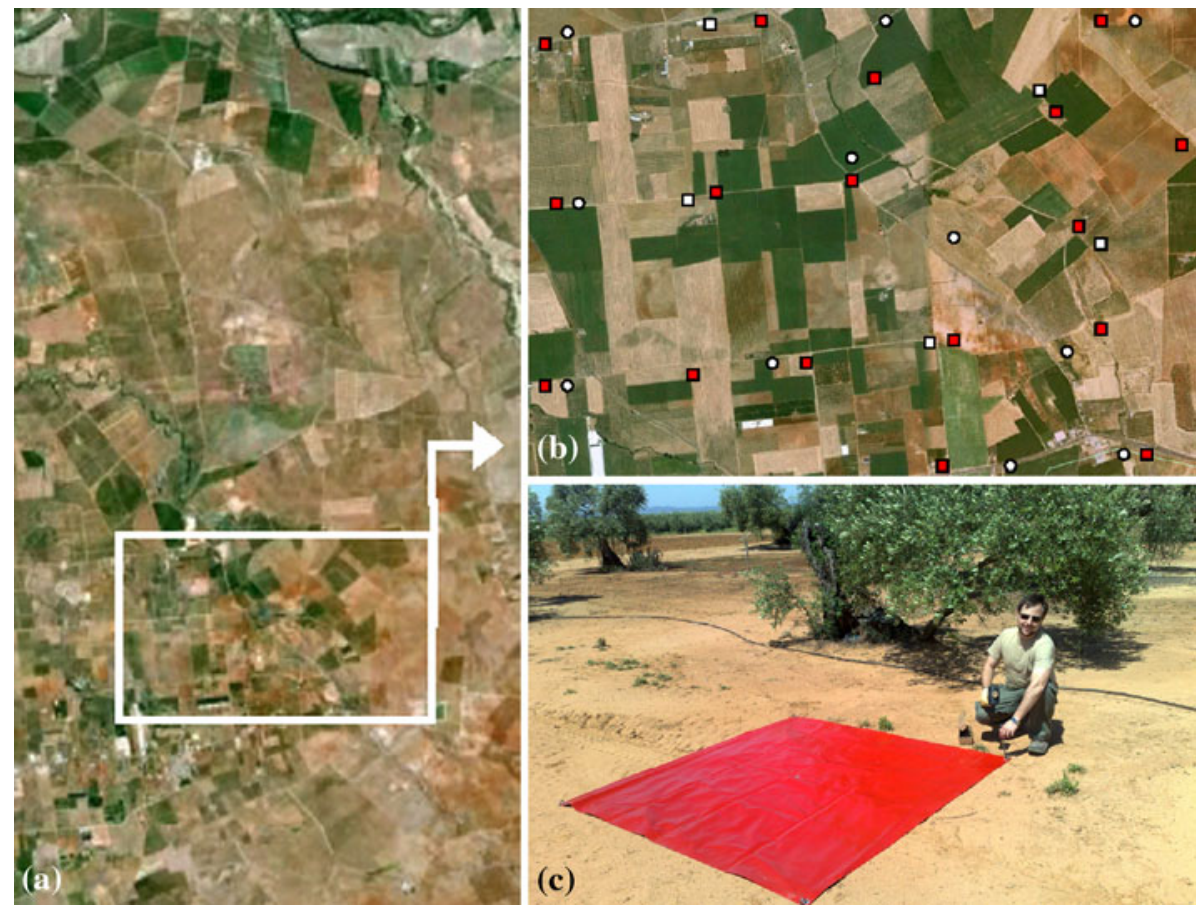

Fig. 1 a A view of the GeoEye-1 satellite at LaVentilla village; b the detail of the approximately 1000 ha area used in the study, where the hard-edge 16 GCPs (11 for geo-referencing and 5 for validation, white circles and white squares, respectively) and 17 pairs of artificial terrestrial targets (ATTs, red squares) were used; $\mathbf{c}$ the placement of the ATT in the field (Color figure online)

Spanish Geo-position Station Network. For each image, the PE and the $\Phi_{\mathrm{ge}}$ of each control point (i) assessed on the ground $\left(X_{\mathrm{GTi}}, Y_{\mathrm{GTi}}\right)$ and in the corresponding remote image $\left(X_{\mathrm{RIi}}\right.$, $Y_{\mathrm{RIi}}$ ) (Fig. 2) were determined by the metric-based Pythagorean Theorem equation (Slama et al. 1980), as follows:

$$
\mathrm{PE}_{\mathrm{i}}=\left[\Delta X_{\mathrm{i}}^{2}+\Delta Y_{\mathrm{i}}^{2}\right]^{1 / 2}
$$

where $\Delta X_{\mathrm{i}}=X_{\mathrm{GTi}}-X_{\mathrm{RIi}}, \Delta Y_{\mathrm{i}}=Y_{\mathrm{GTi}}-Y_{\mathrm{RIi}}$, The overall position error (RMSE) for an image with n GCPS was assessed as follows (ERDAS Inc. 1999):

$$
\operatorname{RMSE}=\left[\sum_{i=1}^{n}\left[\Delta X_{\mathrm{i}}^{2}+\Delta Y_{\mathrm{i}}^{2}\right] / n\right]^{1 / 2}
$$

The error direction angle $\left(\Phi_{\mathrm{ge}}\right)$ of each GCP was calculated by the following equation:

$$
\Phi_{\text {ge i }}^{\circ}=\operatorname{Arctan}\left[\frac{\Delta Y_{\mathrm{i}}}{\Delta X_{\mathrm{i}}}\right] \times\left(\frac{180}{\pi}\right)
$$

The mean, standard deviation (s.d.) and range of the $\mathrm{PE}_{\mathrm{i}}$ and $\Phi_{\mathrm{ge}} \mathrm{i}$ of validation control points for each image and the overall RMSE of images were calculated. To study, 
(a) Agricultural parcel and micro-plot set
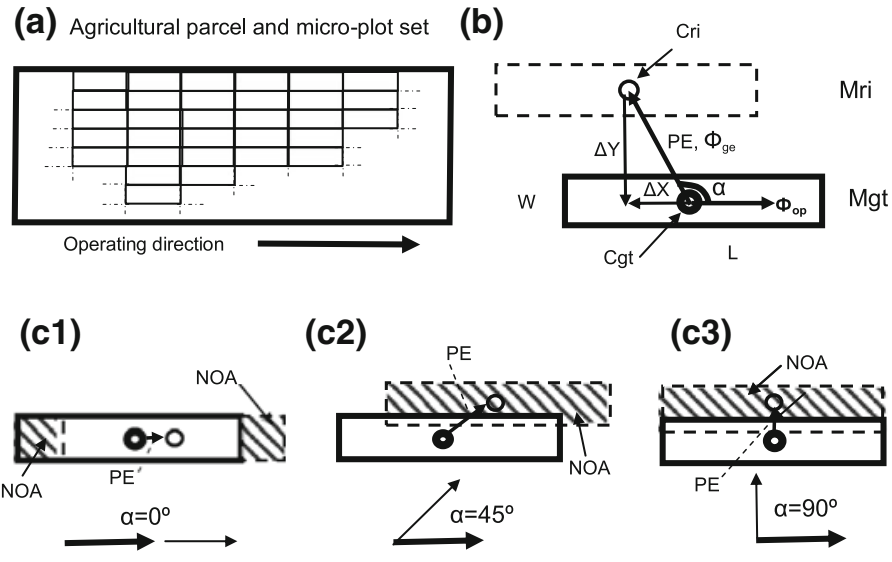

(c2)
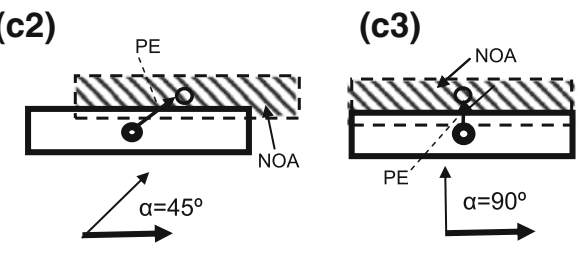

(d)

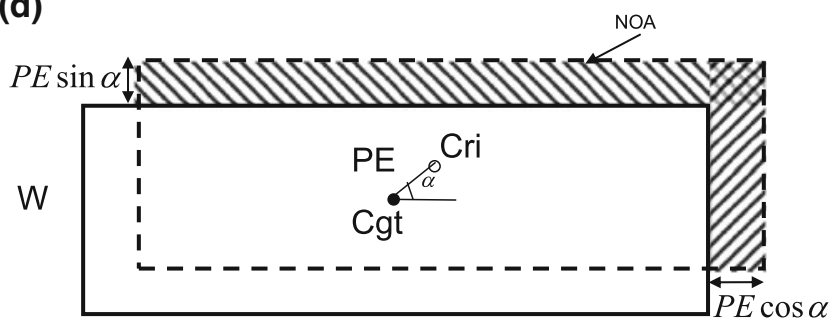

L

Fig. 2 a The micro-plots setting in an agricultural parcel; b the micro-plot ground-truth (Mgt) and microplot remote image (Mri), with an indication of its centres (Cgt and Cri), Length $(L)$, Width $(W)$ and position error (PE); c the overlap of the Mgt and Mri, as affected by the geo-referencing error direction angle (arrow $\Phi_{\mathrm{ge}}$ ) as related to the field operating direction (left right arrow $\Phi_{\mathrm{op}}$ ): (1) parallel, $\alpha=\Phi_{\mathrm{ge}}-\Phi_{\mathrm{op}}=0^{\circ}$; (2) acute, $\alpha \geq 0^{\circ}$ and $\leq 90^{\circ}$, e.g., $=45^{\circ}$; and (3) perpendicular, $\alpha=90^{\circ}$. In each case, the centre "movement" and the "non-overlapping area" (NOA) area indicated; d estimation of the not overlapping area $\left[\mathrm{NOA}=(\mathrm{PE} \cdot \cos \alpha \cdot W)+(\mathrm{PE} \cdot \sin \alpha \cdot L)-\left(\mathrm{PE}^{2} \cdot \sin \alpha \cdot \cos \alpha\right)\right]$ between Mgt and Mri

comparatively, the panchromatic and multi-spectral images taken on the same date, the correlation coefficients of the $\Delta X_{\mathrm{i}}, \Delta Y_{\mathrm{i}}, \mathrm{PE}_{\mathrm{i}}$ and $\Phi_{\text {gei }}^{\circ}$ of both image types for each GCP were calculated and averaged for the GCPs.

Geo-referencing of GeoEye-1 images

\section{Conventional}

Geo-referencing was achieved through the ENVI-4.6 menu MAP/Registration/Warp Select GCPs/Image to Map, using the 11 DGPS-assessed GCPs shown in Fig. 1b and then validating the results with 5 DGPS-assessed GCPs. A linear/first-order function was applied for the geo-referencing using the nearest neighbor re-sampling methods (Hughes et al. 2006). The validation of the geo-referencing process was assessed for each GCP, and the PE/RMSE and $\Phi_{\mathrm{ge}}^{\circ}$ were calculated as previously described (Slama et al. 1980; ERDAS Inc. 1999). 


\section{$A U G E O^{\circledR}$ and image to image system}

The artificial terrestrial targets (ATTs) consisted of a couple of square tarps, $4.0 \mathrm{~m}^{2}$ in area, each white and red (Fig. 1c). Each ATT was placed in the image scene and geo-referenced using a sub-decimetre DGPS Trimble GEO-XH receiver as previously described. A total of 17 red ATTs were evenly distributed in the 4-May GeoEye-1 image (Fig. 1b) as training GCPs for the image geo-referencing, and 17 white ATTs were used for validation. The GeoEye-1 panchromatic and multi-spectral images were then processed using the AUGEO $^{\circledR}$ add-on software (Gómez-Candón et al. 2011). The geo-referenced image will be hereafter known as the 4-May AUGEO-image. The other six GeoEye-1 images of the studied series were co-registered through the ENVI menu "image to image" and taken as image references for the 4-May GeoEye-1. A linear/first-order function was applied for the geo-referencing using the nearest neighbor re-sampling methods (Hughes et al. 2006). The validation of the geo-referencing process was assessed based on five DGPS-assessed GCPs; for each GCP, the total PE and error direction angle $\left(\Phi_{\text {ge }}^{\circ}\right)$ were estimated as previously described (Slama et al. 1980; ERDAS Inc. 1999).

\section{IPM errors from remote-sensed images: the case of GeoEye-1}

In precision agriculture, the IPMs are normally made up of reduced-size (i.e., 2-400 $\mathrm{m}^{2}$ ), rectangular-shaped micro-plots (Fig. 2a). Each ground micro-plot (Mgt) is defined by its length $(L)$, width $(W)$, its ground geographic centre co-ordinates $\left(\mathrm{Cgt}, \mathrm{Xg}_{\mathrm{i}}\right.$, and $\left.\mathrm{Yg}_{\mathrm{i}}\right)$, and its orientation $\left(\Phi_{\text {ge }}\right.$, geo-referencing error angle) (Fig. 2b). Similarly, its corresponding remote image micro-plot (Mri) is defined by its $L, W$ and geographic centre co-ordinates $\left(\mathrm{Cr}_{\mathrm{i}}, \mathrm{Xr}_{\mathrm{i}}\right.$, and $\left.\mathrm{Yr}_{\mathrm{i}}\right)$. The corresponding geographic co-ordinates of the centres, $\mathrm{Mg}_{\mathrm{ti}}$ and $\mathrm{Mr}_{\mathrm{ii}}$, normally do not coincide as a result of geo-referencing errors, which are defined by its error and the angle $\left(\alpha^{\circ}\right)$ between the machinery-operating direction $\left(\Phi_{\text {op }}^{\circ}\right)$ and the error direction $\left(\Phi_{\text {ge }}^{\circ}\right)$, where $\alpha^{\circ}=\Phi_{\text {ge }}^{\circ}-\Phi_{\text {op }}^{\circ}$ (Fig. 2c).

The IPM inaccuracy was estimated by the percentage of non-overlapped area (\%NOA) between the remote image micro-plot $\left(M_{\mathrm{RI}}\right)$ and its corresponding ground-truth micro-plot $\left(M_{\mathrm{GT}}\right)$ using the geo-referencing error (Fig. 2c, d), which is defined by the following equation:

$$
\% \mathrm{NOA}=\frac{\left[(\mathrm{RMSE} \cdot \cos \alpha \cdot W)+(\mathrm{RMSE} \cdot \sin \alpha \cdot L)-\left(\mathrm{RMSE}^{2} \cdot \sin \alpha \cdot \cos \alpha\right)\right]}{W \cdot L} \cdot 100
$$

The $\%$ NOA was assessed as affected by a PE from 1 to $8 \mathrm{~m}, L$ from 1 to $40 \mathrm{~m}$ and $\alpha^{\circ}$ from 0 to $90^{\circ}$, assuming that $W$ was equal to $6 \mathrm{~m}$. The micro-plot size that was required to obtain a \%NOA of $<10 \%$ for the GeoEye- 1 series studied here was also estimated.

\section{Results}

Positioning errors of the GeoEye-1 images

The PE and $\Phi_{\mathrm{ge}}^{\circ}$ for each GCP varied slightly for any GeoEye-1 image and varied considerably between images taken on different dates (Table 1; data for each GCP not shown for abbreviation). For the panchromatic image taken on 9-April, the PE and $\Phi_{\mathrm{ge}}^{\circ}$ of GCPs $\# 1$ and \#2 were $11.16 \mathrm{~m}$ and $356.9^{\circ}$ and $7.04 \mathrm{~m}$ and $349.6^{\circ}$, respectively. The RMSE and 
$\Phi_{\text {ge }}^{\circ}$ varied considerably between the panchromatic images averaged over the GCPs, ranging from $1.90 \mathrm{~m}$ and $310.9^{\circ}$ on the 4-May image to $8.87 \mathrm{~m}$ and $87.1^{\circ}$ on the 20-June image; similar results were obtained for the multi-spectral series (Table 1). The average RMSE and $\Phi_{\mathrm{ge}}^{\circ}$ were $5.93 \mathrm{~m}$ and $229.6^{\circ}$ and $6.46 \mathrm{~m}$ and $233.2^{\circ}$ for the panchromatic and multi-spectral series, respectively. Each GCP for the panchromatic and multi-spectral images taken the same date showed a similar tendency of data variation regarding the PE and $\Phi_{\mathrm{ge}}^{\circ}$ parameters (data not shown for abbreviation). The correlation coefficients between the $\Delta X, \Delta Y, \mathrm{PE}$ and $\Phi_{\mathrm{ge}}^{\circ}$ for each GCP between the panchromatic and multi-spectral image were $0.9,0.9,0.8$ and 0.8 overall of the images, respectively. Therefore, the RMSE and $\Phi_{\mathrm{ge}}^{\circ}$ may be assessed in either panchromatic or multi-spectral images, but not necessarily in both.

Geo-referencing of the GeoEye-1 images

\section{Conventional}

The RMSE of original images geo-referenced using ground-control-points (CGP) ranged from $0.94 \pm 0.35$ to $3.21 \pm 2.12 \mathrm{~m}$ for the panchromatic images and from $2.70 \pm 1.30$ to $4.17 \pm 1.75 \mathrm{~m}$ for the multi-spectral images (Table 1). Similarly, the $\Phi_{\mathrm{ge}}^{\circ}$ varied between the images from both series, from approximately 72.8 to 124.4 and 88.6 to $147.1^{\circ}$, respectively. The overall RMSE and $\Phi_{\text {ge }}^{\circ}$ over the seven images were $1.78 \mathrm{~m}$ and $113.7^{\circ}$ and $3.36 \mathrm{~m}$ and $116.6^{\circ}$ for the panchromatic and multi-spectral series, respectively.

\section{AUGEO ${ }^{\circledR}$ system}

The overall RMSE obtained through the implementation of the AUGEO system for the 4-May image was 0.75 with an s.d. of the individual validation points of $0.24 \mathrm{~m}$ for the panchromatic image, and 2.70 and $0.87 \mathrm{~m}$ for the same statistics for the multi-spectral image, respectively.

\section{Image-to-image co-registration (ITI)}

GeoEye-1 images were co-registered taking the AUGEO-May-04 image as the reference. It resulted in an average RMSE of 3.16 and $4.74 \mathrm{~m}$ for the panchromatic and the multispectral images series, with values that ranged from 2.32 to $4.61 \mathrm{~m}$ and from 3.56 to $5.99 \mathrm{~m}$, respectively (Table 1). The $\Phi_{\text {ge }}^{\circ}$ values were very similar for images taken on the same date, and the averages were 124.7 and $130.8^{\circ}$ for the panchromatic and multi-spectral image series, respectively.

\section{Prescription map errors from remote-sensed images: the case of GeoEye-1}

The IPM inaccuracy resulting from the geo-referencing error was consistently affected by the PE, $\alpha^{\circ}$ and the micro-plot size. The \%NOA consistently increased as the RMSE and $\alpha^{\circ}$ increased and, conversely, decreased as the micro-plot increased (Fig. 3a). Assuming a micro-plot width $W$ equal to $6 \mathrm{~m}$ and an error direction coinciding with the machinery operational direction $\left(\alpha^{\circ}=0^{\circ}\right)$, if the RMSE was 2 and $5 \mathrm{~m}$, the $L$ should be approximately 15 and $30 \mathrm{~m}$ (or higher), respectively, to obtain a \%NOA value of $<10 \%$ (Fig. 3a). 


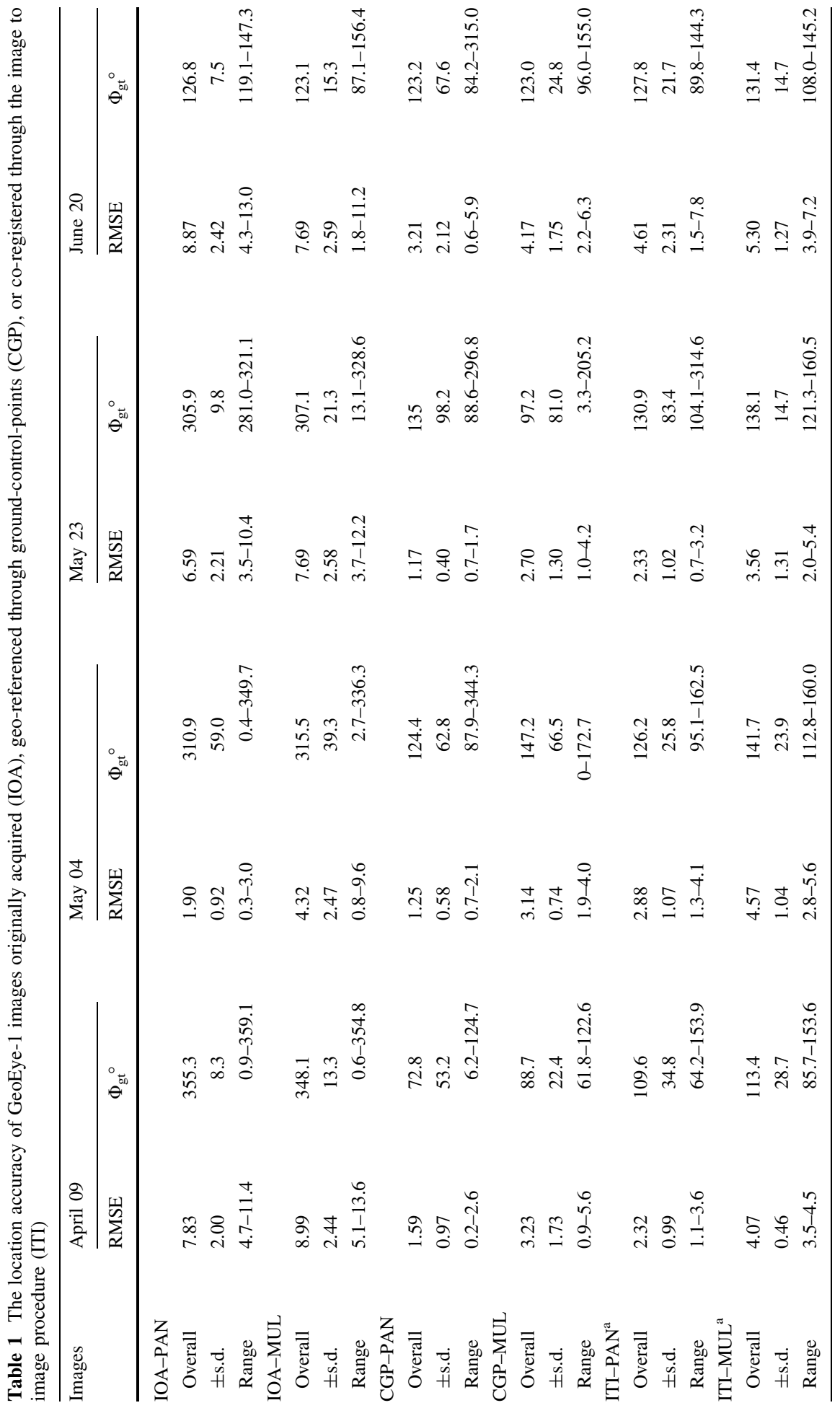




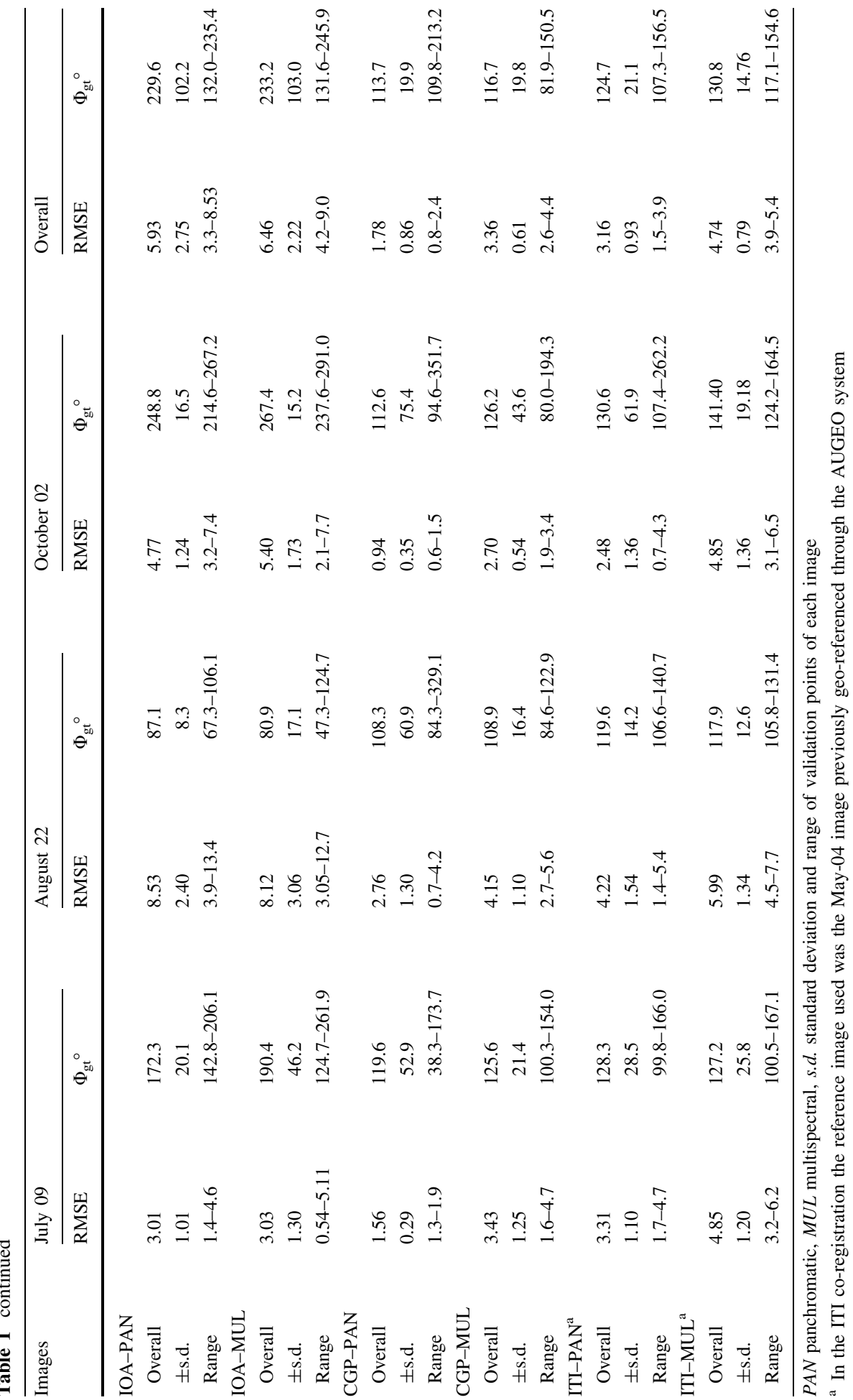


The angle, $\alpha^{\circ}$, considerably affected the $\%$ NOA, increasing it as the absolute $\sin \alpha^{\circ}$ values increased from 0 to 1 . If the error direction was perpendicular to the operational direction ( $\left|\sin \alpha^{\circ}\right|=1$ ), for a $\mathrm{PE}=1$, the minimum $\%$ NOA would be approximately $20 \%$, regardless of the micro-plot size, and would, therefore, be unacceptable. For a $\alpha^{\circ}$ of approximately $30^{\circ}$ and a $W=30 \mathrm{~m}$, the $L$ should be $\geq 15 \mathrm{~m}$ to obtain a $\%$ NOA of approximately 10 to $15 \%$. The $\% \mathrm{NOA}$ increased as the $\alpha^{\circ}$ increased. For example, if the PE was $3 \mathrm{~m}$ and the $W=6 \mathrm{~m}$ and $L=40 \mathrm{~m}$, the $\%$ NOA would be approximately $\leq 10$ and $50 \%$ for $\alpha^{\circ}$ values of 0 and $90^{\circ}$, respectively (Fig. 3b). In the case of the GeoEye- 1 images studied with an average PE of $6 \mathrm{~m}$, a micro-plot size of $30 \times 6 \mathrm{~m}$ would have yielded an IPM inaccuracy (\% NOA) of approximately $5 \%$, assuming the $\alpha^{\circ}=0^{\circ}$.

\section{Discussion}

Precision agriculture operations require IPM delineated from high-spatial-resolution images (i.e., $<3 \mathrm{~m} \mathrm{pixel}^{-1}$ ) and accurately geo-referenced (ideally errors $<1-2 \mathrm{~m}$ ). According to the data described here, the average position accuracy of GeoEye- 1 satellite images were approximately $6.0-6.5 \mathrm{~m}$, with a variable orientation of approximately $0-30^{\circ}$, which can be considered unacceptable, or barely acceptable, to achieve precise SSM. Therefore, this
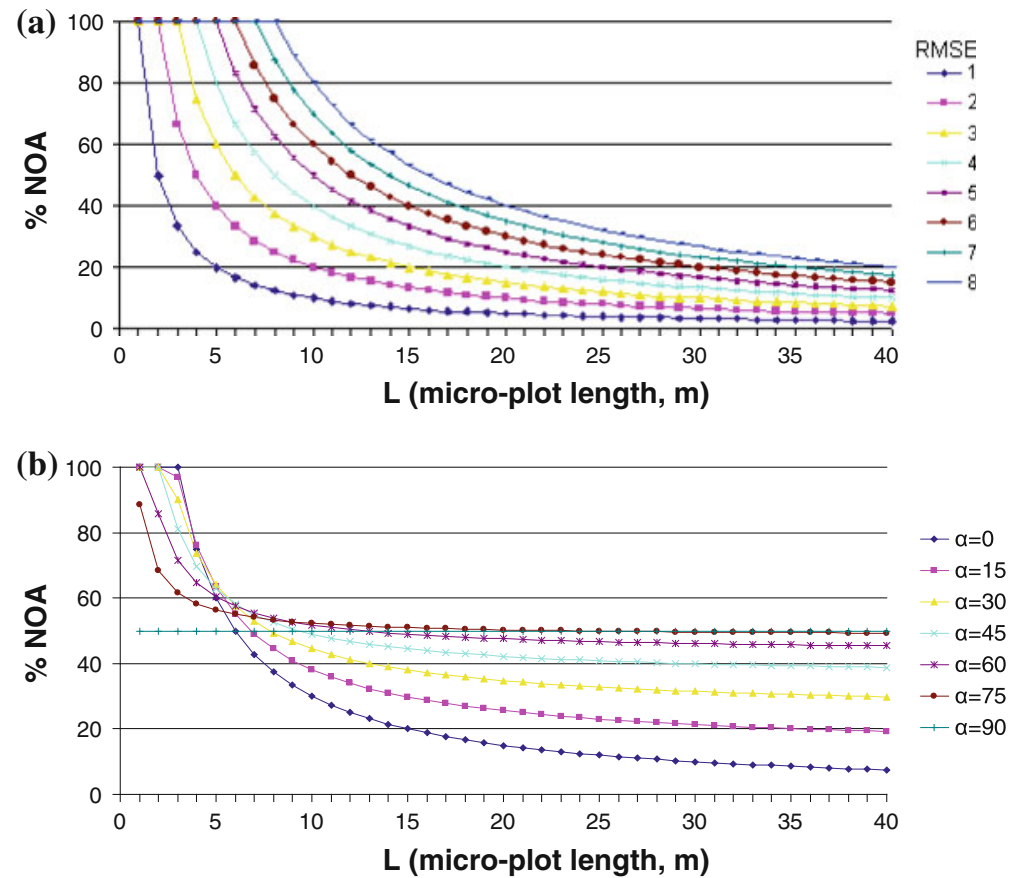

Fig. 3 a The $\%$ of micro-plot non-overlapping area (\%NOA), as affected by the RMSE and the micro-plot length ( $L$ from 1 to $40 \mathrm{~m}$ ), assuming that the micro-plot width $W$ is $6 \mathrm{~m}$ and the $\alpha$, the geo-referencing error direction angle, as related to the field operating direction, is $0^{\circ}$. $\mathbf{b}$ The $\%$ of micro-plot non-overlapping area (\%NOA), as affected by the micro-plot length ( $L$ from 1 to $40 \mathrm{~m}$ ) and the geo-referencing error direction angle, as related to the field operating direction $(\alpha)$, assuming that the micro-plot width $W$ is $6 \mathrm{~m}$ and the RMSE is $3 \mathrm{~m}$ 
procedure is in agreement with other authors, such as Toutin and Chénier (2004), Hughes et al. (2006) and Weber et al. (2008), who are very concerned about the need to use accurate training-site locations for geo-referencing remotely-sensed images. In general, with the current DGPS-technology, most remote images captured from satellites, conventional airplanes and UAV platforms hardly meet the position accuracy required and, consequently, additional geo-referencing effort is needed for site-specific management (Gómez-Candón et al. 2011).

According to data herein described, the conventional and AUGEO system geo-referencing processes partially reduced the position error only to approximately 60 or $40 \%$, respectively; thus, additional geo-referencing is advisable to increase the positioning accuracy. These results are in accordance with previous geo-referencing studies by other authors who have used "hard edge" GCPs (Toutin and Chénier 2004; Hughes et al. 2006) or ATTs in the case of the AUGEO system (Gómez-Candón et al. 2011). However, both conventional and AUGEO geo-referencing processes require considerable human effort. Conventional geo-referencing requires identifying and geo-referencing hard-edged GCPs when they are available for the studied area. If the same image scene needs to be georeferenced several times successively, the same GCPs need to be geo-referenced by DGPS only once, thus, avoiding twice the field work and considerably decreasing the costs. Alternatively, the semi-automatic AUGEO system requires the display in the scene of an ATT, and it is particularly advisable for areas that lack easily identifiable GCPs (GómezCandón et al. 2011). An obvious improvement to the system would be the development of "automatic ATTs" with a permanent or semi-permanent positioning that will automatically display the light-reflectance source, whether a coloured tarp or a battery-powered light, only at the approximate time that the remote-sensed image is captured.

An IPM created from a remote image is a key technological device that has to be transferred to the input application machinery. The \%NOA notably increased as the georeferencing error increased and, conversely, decreased as the micro-plot length increased. One way to overcome the position error is by increasing the micro-plot size, particularly its $L$, as the $W$ is adjusted to the application-machinery nozzle width and nozzle-activating technology. However, as micro-plot size was increased, the environmental and economic potential benefits of SSM decreased, as shown by Gómez-Candón et al. (2011b).

The angle, $\alpha^{\circ}$, created between the direction of the operating machinery and the locational error direction consistently affected the untreated area of the micro-plots. Because the $\% \mathrm{NOA}$ increased as the direction angle error increased, the direction of the movement of the input application machinery is a key parameter to determine the \%NOA. Thus, if an error direction is nearly perpendicular to the traditional or standard field operational direction of the micro-plots, it could be advisable to change the operational direction to fit with the error direction.

\section{Conclusions}

Satellite GeoEye-1 images due to their spatial and spectral resolution have significant potential for precision agriculture uses. In these studies, the average locational and angular errors for the GeoEye-1 images were approximately $6.0 \mathrm{~m}$ and $230^{\circ}$ for both the panchromatic and multi-spectral series of images, which could be taken into account in the delineation of the IPM. Furthermore, important differences were found in the positional errors among the GeoEye-1 images and slight differences between the GCPs within any given GeoEye-1 image. Thus, image geo-referencing improvement is recommended to 
reduce the geographical error between the remote image and the ground. The results showed that conventional geo-referencing using GCPs provided a positioning error of 0.94 for the panchromatic to $4.17 \mathrm{~m}$ for the multi-spectral image series, and similarly the AUGEO System ${ }^{\circledR}$ of $0.75-2.70 \mathrm{~m}$, and ITI co-registration of $2.32-5.99 \mathrm{~m}$, respectively.

The IPM delineated from remote-sensed images takes up the image geo-referencing error; consequently, a portion of each IPM micro-plot does not overlap (\%NOA) with its corresponding ground-truth micro-plot. Furthermore, the $\%$ NOA has been estimated as a function of the RMSE, $\alpha^{\circ}, W$ and $L$, and it has been demonstrated that micro-plot size, particularly its $L$ and orientation $\left(\alpha^{\circ}\right)$, should be adapted or conditioned to the geo-referencing error in both the magnitude (RMSE) and direction of the ground operating machinery.

Acknowledgments This research was partially financed by the Spanish Ministry of Science and Innovation through Project AGL2010-15506.

Open Access This article is distributed under the terms of the Creative Commons Attribution License which permits any use, distribution, and reproduction in any medium, provided the original author(s) and the source are credited.

\section{References}

Brown, R. B., \& Noble, S. D. (2005). Site-specific weed management: Sensing requirements-what do we need to see? Weed Science, 53, 252-258.

ERDAS Inc. (1999). RMS error, page 362-365, in ERDAS field guide (5th ed., p. 672). Atlanta, GA: ERDAS Inc.

GeoEye (2011). Satellite and aerial images provider. Dulles, VA: GeoEye. http://www.geoeye.com/ CorpSite/. Accessed 15 Mar 2012.

Gómez-Candón, D., López-Granados, F., Caballero-Novella, J. J., García-Ferrer, A., Peña-Barragán, J. M., Jurado-Expósito, M., et al. (2011a). Sectioning remote imagery for characterization of Avena sterilis infestations. Part A: Efficiency and economics control. Precision Agriculture, 13(3), 322-336.

Gómez-Candón, D., López-Granados, F., Caballero-Novella, J. J., García-Ferrer, A., Peña-Barragán, J. M., Jurado-Expósito, M., et al. (2011b). Sectioning remote imagery for characterization of Avena sterilis infestations. Part B: Efficiency and economics control. Precision Agriculture, 13(3), 337-350.

Gómez-Candón, D., López-Granados, F., Caballero-Novella, J. J., Gómez-Casero, M., Jurado-Expósito, M., \& García-Torres, L. (2011c). Geo-referencing remote images for precision agriculture using artificial terrestrial targets. Precision Agriculture, 12(6), 876-891.

Hughes, M. L., McDowell, P. F., \& Marcus, W. A. (2006). Accuracy assessment of georectified aerial photographs: Implications for measuring lateral channel movement in a GIS. Geomorphology, 74, $1-16$.

Lamb, D. W., \& Brown, R. B. (2001). Remote-sensing and mapping of weed in crops. Journal Agricultural Engineering Research, 78, 117-125.

Lamb, D. W., Weedon, M. M., \& Rew, L. J. (1999). Evaluating the accuracy of mapping weeds in seedling crops using airborne digital imaging Avena spp. in seedling triticale (X. triticosecale). Weed Research, 39, 481-492.

López-Granados, F., Jurado-Expósito, M., Peña-Barragán, J. M., \& García-Torres, L. (2006). Using remote sensing for identification of late-season grass weed patches in wheat. Weed Science, 54, 346-353.

Rew, L. J., Miller, P. C. H., \& Paice, M. E. R. (1997). The importance of patch mapping resolution for sprayer control. Aspects of Applied Biology, 48, 49-55.

Ruiz, D., Escribano, C., \& Fernández-Quintanilla, C. (2006). Assessing the opportunity for site-specific management of Avena sterilis in winter barley fields in Spain. Weed Research, 46, 379-387.

SIC (2011). Satellite Image Corporation. Magnolia, TX: SIC. http://www.satimagingcorp.com/galleryquickbird.html. Accessed 15 Mar 2012.

Slama, C. C., Theurer, C., \& Henriksen, S. W. (1980). Manual of photogrammetry (4th ed.). Bethesda, MD: The American Society for Photogrammetry and Remote Sensing. 
Toutin, T. H., \& Chénier, R. (2004). GCP requirement for high resolution satellite mapping. In Orhan Altan (Ed.), Proceedings International Society for Photogrammetry and Remote Sensing Congress, Istanbul, 35(3), 836-839.

Weber, K. T., Théau, J., \& Serr, K. (2008). Effect of coregistration error on patchy target detection using high-resolution imagery. Remote Sensing of Environment, 112, 845-850. 